\title{
A genetic variant in the gene encoding fibrinogen beta chain predicted development of hypertension in Chinese men
}

\author{
Kwok Leung Ong'; Annette W. K. Tso'; Stacey S. Cherny²; Pak Chung Sham²; Karen S. L. Lam'; Chao Qiang Jiang33; G. Neil Thomas"; \\ Tai Hing Lam ${ }^{5}$; Bernard M. Y. Cheung ${ }^{1}$ \\ ${ }^{1}$ Department of Medicine, University of Hong Kong, Hong Kong; ${ }^{2}$ Department of Psychiatry and Genome Research Centre, University of Hong Kong, Hong Kong; ${ }^{3}$ Guangzhou \\ no. 12 Hospital, Guangzhou, China; ${ }^{4}$ Department of Public Health and Epidemiology, University of Birmingham, UK; ${ }^{5}$ Department of Community Medicine, University of Hong \\ Kong, Hong Kong
}

\begin{abstract}
Summary
Fibrinogen, a major determinant of blood viscosity, is an acute phase protein associated with cardiovascular disease. We studied the association of hypertension with single nucleotide polymorphisms (SNPS) in the gene encoding the fibrinogen $\beta$ chain (FGB). Three tagging SNPs (rs1025154, rs4220 and rs1044291) were selected from the HapMap database on Han Chinese. Genotypes were determined in 1,294 unrelated subjects from the Hong Kong Cardiovascular Risk Factor Prevalence Study cohort. There were 199 hypertensive subjects at baseline. Among 1,095 subjects normotensive at baseline, 178 developed hypertension during a median follow-up period of 6.4 years. Among the three tagging SNPs, rs4220 showed significant association with hypertension at both baseline (odds ratio $[\mathrm{OR}]=1.49, \mathrm{p}=0.004$ ) and at follow-up
\end{abstract}

$(O R=1.32, p=0.013)$. The minor $A$ allele of this SNP was associated with higher plasma fibrinogen level $(\beta=0.144, p<0.001$ at baseline and $\beta=0.130, p<0.001$ at follow-up). Among subjects normotensive at baseline, this SNP was also associated with the development of hypertension in men ( $O R=1.52, p=0.022)$, but not in women. The SNP rs4220 in $F G B$, which leads to the substitution of arginine by lysine at position 448 , is independently associated with plasma fibrinogen level and hypertension in Hong Kong Chinese. This suggests a possible causal role of fibrinogen in hypertension development, especially in men.

\section{Keywords}

Fibrinogen, hypertension, single nucleotide polymorphisms

\section{Correspondence to:}

Prof. Bernard M. Y. Cheung

University Department of Medicine

Queen Mary Hospital, Hong Kong

Tel.: +852 22554347, Fax: +852 28186474

E-mail: mycheung@hku.hk
Financial support:

The Hong Kong Cardiovascular Risk Factor Prevalence Study-2 was funded by Hong Kong Research Grant Council grants (HKU7229/01M and HKU7626/07M), and the Sun Chieh Yeh Heart Foundation. The genotyping of SNPs in the FGB gene was supported by a grant from the National Natural Science Foundation of China/Research Grants Council of Hong Kong Joint Research Scheme (30518001/C0301070202 and HKU720/05).

Received: October 8, 2009

Accepted after major revision: December 1, 2009

Prepublished online: February 2, 2010

doi:10.1160/TH09-10-0692

Thromb Haemost 2010; 103: 728-735

\section{Introduction}

Fibrinogen, a major determinant of blood viscosity, is an acute phase protein associated with cardiovascular disease and the metabolic syndrome $(1,2)$. Previous studies have shown consistently that fibrinogen can predict the development of cardiovascular diseases such as coronary heart disease, stroke and myocardial infarction, as well as related mortality (3). Fibrinogen consists of three polypeptide chains, $\alpha, \beta$ and $\gamma$, among which the synthesis of the $\beta$ chain is the rate-limiting step in the synthesis of mature fibrinogen (4). The genes encoding the three polypeptide chains are clustered together in a $55 \mathrm{~kb}$-region on the chromosome 4q23-32 (5). Genetic variants in the gene encoding the fibrinogen $\beta$ chain $(F G B)$ such as $-455 \mathrm{G}>\mathrm{A}$ and $-148 \mathrm{C}>\mathrm{T}$ have been shown to be associated with plasma fibrinogen levels in different studies (6). However, there have been relatively few reports on the role of fibrinogen in hypertension. Some of the previous cross-sectional studies demonstrated positive association of plasma fibrinogen with hypertension, but some did not $(7,8)$. There were two prospective studies which reported positive association of plasma fibrinogen with development of hypertension in men, but not in women $(7,9)$. For genetic association study, a recent cross-sectional study in Germany reported that genetic variants in the FGB gene were not associated with hypertension although a genetic variant in the fibrinogen $\alpha$ chain showed a significant association in women only, but not in men (8). To the best of our knowledge, there are few reports on the relationship of hypertension and fibrinogen in Chinese populations (10), and none examining the association of genetic variants of fibrinogen with hypertension in Chinese. 
We previously reported the association of genetic variants in the FGB gene with impaired glucose tolerance in Hong Kong Chinese (11). We also recently reported that dysglycaemia and raised blood pressure co-exist in a large proportion of subjects in the population-based Hong Kong Cardiovascular Risk Factor Prevalence Study-2 (CRISPS-2) cohort (12). In this cohort, 58\% subjects with diabetes had raised blood pressure and $56 \%$ subjects with hypertension had dysglycaemia (12). Age, systolic blood pressure and two-hour glucose level after oral glucose tolerance test (OGTT) were independent predictors of the development of hypertension (12). Therefore, we hypothesised that genetic variants in the FGB gene may be associated with hypertension in our population. We genotyped three tagging single nucleotide polymorphisms (SNPs) in 1,294 subjects from the CRISPS-2 cohort and studied their associations with hypertension.

\section{Methods}

\section{Subjects}

In the Hong Kong Cardiovascular Risk Factor Prevalence Study (CRISPS), a random sample of 2,895 Hong Kong Chinese subjects were recruited from the general population in 1995-1996 and 1944 of them enrolled in the follow-up study (CRISPS-2) in 2000-2004 after a median interval of 6.4 years (12-15). Among the 1,944 subjects in the CRISPS-2 study, DNA samples were available in 1,938 subjects and 1,299 of them had plasma fibrinogen level measured at both baseline and follow-up. Five subjects were further excluded from the study as they had less than two out of the three SNPs successfully genotyped. Therefore, a total of 1,294 subjects were included in the analysis. The study protocol was approved by the Ethics Committee of the University of Hong Kong. The study complies with the Declaration of Helsinki. All subjects gave written, informed consent.

\section{SNP selection and genotyping}

From the HapMap data on the Han Chinese population (Phase II data, release 23) (16), three tagging SNPs in the FGB gene with a minor allele frequency (MAF) $\geq 0.05$ were identified ( $r s 1025154$, rs4220 and rs1044291). These three tagging SNPs captured all the 15 SNPs from $5 \mathrm{~kb}$ upstream to $2 \mathrm{~kb}$ downstream of the gene (position 155,698,596-155,713,688, GenBank accession number NC_000004, NCBI 36) with $r^{2} \geq 0.9$ and MAF $\geq 0.05$ (see Supplementary Table 1 available online at www.thrombosis-online.com). Genotyping was performed using a MassARRAY system (Sequenom, San Diego, CA, USA) and an iPLEX ${ }^{\mathrm{TM}}$ assay in the Genome Research Centre, The University of Hong Kong. All the nucleotide sequences were based on the forward strand of sequence from the GenBank accession number NC_000004.

\section{Statistical analysis}

Subject characteristics were compared using unpaired student's t-test or Mann-Whitney U test for continuous variables, and chisquare test for categorical variables using SPSS 15.0 (SPSS Inc., Chicago, IL, USA). Haploview version 4.1 was used to calculate linkage disequilibrium (LD) and select the tagging SNPs (17). Haplotype analysis was performed using the program PLINK (version 1.0.6) (18). Only haplotypes with frequency $>0.05$ were tested. In PLINK, logistic or linear regression models were used to estimate the odds ratios (OR) or unstandardised regression coefficients under the assumption of an additive effect of allele dosage. For single variant analysis, standardised regression coefficients $(\beta)$ were also estimated. For variables with a skewed distribution, the logarithms were used in analysis. The SNP spectral decomposition method (SNPSpD) was used to correct for multiple testing in single variant analysis (19). The effective number of independent marker loci was 2.605 and the experimental-wide significance threshold to keep type 1 error rate at $5 \%$ was 0.0192 . For sex-specific analysis, the threshold was 0.0096 under this method.

\section{Results}

\section{Subject characteristics}

In this study, the prevalence of hypertension was $15.4 \%$ at baseline and $26.9 \%$ at follow-up. As expected, hypertensive subjects had significantly higher mean age, body mass index (BMI), waist circumference, blood pressure, plasma triglycerides, fasting glucose, two-hour glucose after OGTT, fasting insulin and homeostasis model assessment of insulin resistance index (HOMA-IR), and reduced high-density lipoprotein (HDL)-cholesterol ( Table 1). The plasma fibrinogen level was significantly associated with hypertension ( $\mathrm{p}=0.012$ at baseline and $\mathrm{p}=0.032$ at follow-up).

\section{Genotyping and LD}

The genotyping rates were $\geq 99.8 \%$ for all the SNPs. The MAFs of rs1025154, rs4220 and rs 1044291 were $47.7 \%, 27.0 \%$ and $11.5 \%$, respectively. None of the SNPs showed significant deviation from Hardy-Weinberg equilibrium among all subjects or among caseand control-specific subgroups at both baseline and follow-up ( $p>0.05$ ). The SNP rs1025154 showed a significantly higher MAF in this study than that in the HapMap Han Chinese population $(\mathrm{p}=0.007)$. None of the SNP pairs showed moderate or high pairwise $\mathrm{LD}$ with each other $\left(r^{2} \leq 0.40\right.$ for all SNP pairs with the average $r^{2}$ value of 0.197 and $D^{\prime} \geq 0.99$ for all SNP pairs) ( Fig. 1). The pairwise LD pattern in our population was similar to that in the HapMap Han Chinese population ( $p>0.05$ for all the three SNP pairs). There were four common haplotypes with frequency $>0.05$, namely, CGC (0.522), TAC (0.269), TGT (0.115) and TGC (0.093) 


\begin{tabular}{|c|c|c|c|c|}
\hline & \multicolumn{2}{|l|}{ Baseline } & \multicolumn{2}{|l|}{ Follow-up } \\
\hline & $\begin{array}{l}\text { Normotensive } \\
(n=1,095)\end{array}$ & $\begin{array}{l}\text { Hypertensive } \\
(n=199)\end{array}$ & $\begin{array}{l}\text { Normotensive } \\
(n=945)\end{array}$ & $\begin{array}{l}\text { Hypertensive } \\
(\mathrm{n}=349)\end{array}$ \\
\hline Age, years & $42.3 \pm 10.8$ & $56.9 \pm 10.5^{\ddagger}$ & $48.6 \pm 10.8$ & $59.5 \pm 10.9^{\ddagger}$ \\
\hline Women, \% & 52.0 & 47.7 & 53.2 & 46.1 \\
\hline $\mathrm{BMI}, \mathrm{kg} / \mathrm{m}^{2}$ & $23.6 \pm 3.3$ & $26.1 \pm 3.7^{\ddagger}$ & $23.4 \pm 3.3$ & $25.4 \pm 3.4^{\ddagger}$ \\
\hline Waist circumference, $\mathrm{cm}$ & $77.0 \pm 9.5$ & $85.2 \pm 9.9^{\ddagger}$ & $78.2 \pm 9.7$ & $84.9 \pm 9.3^{\ddagger}$ \\
\hline Systolic blood pressure, $\mathrm{mmHg}^{\S}$ & $111.8 \pm 12.4$ & $149.6 \pm 12.1^{\ddagger}$ & $114.3 \pm 11.2$ & $148.4 \pm 15.2^{\ddagger}$ \\
\hline Diastolic blood pressure, $\mathrm{mmHg}^{\S}$ & $71.2 \pm 8.4$ & $88.1 \pm 8.4^{\ddagger}$ & $72.5 \pm 8.1$ & $89.5 \pm 10.6^{\ddagger}$ \\
\hline Triglycerides, mM & $0.97(0.94-1.00)$ & $1.32(1.23-1.42)^{\ddagger}$ & $1.10(1.06-1.13)$ & $1.48(1.40-1.56)^{\ddagger}$ \\
\hline Total cholesterol, mM & $4.96 \pm 0.98$ & $5.42 \pm 0.97$ & $5.24 \pm 0.93$ & $5.40 \pm 0.94$ \\
\hline HDL-cholesterol, mM & $1.28 \pm 0.32$ & $1.21 \pm 0.34^{*}$ & $1.39 \pm 0.38$ & $1.27 \pm 0.36^{\ddagger}$ \\
\hline LDL-cholesterol, mM & $3.16 \pm 0.83$ & $3.53 \pm 0.89$ & $3.21 \pm 0.82$ & $3.35 \pm 0.84$ \\
\hline Fasting glucose, mM & $5.16(5.11-5.21)$ & $6.04(5.82-6.28)^{\ddagger}$ & $5.16(5.11-5.21)$ & $5.81(5.67-5.96)^{\ddagger}$ \\
\hline 2-h glucose, mM & $5.74(5.63-5.86)$ & $7.55(6.98-8.17)^{\ddagger}$ & $6.48(6.33-6.62)$ & $8.30(7.95-8.67)^{\ddagger}$ \\
\hline Fasting insulin, mIU/l & $4.45(4.28-4.64)$ & $6.19(5.54-6.91)^{\ddagger}$ & $6.77(6.55-6.99)$ & $9.22(8.66-9.82)^{\ddagger}$ \\
\hline HOMA-IR & $1.02(0.98-1.07)$ & $1.66(1.47-1.88)^{\ddagger}$ & $1.55(1.50-1.61)$ & $2.38(2.21-2.56)^{\ddagger}$ \\
\hline Fibrinogen, $g / l$ & $2.47 \pm 0.55$ & $2.78 \pm 0.67^{*}$ & $2.92 \pm 0.56$ & $3.13 \pm 0.65^{*}$ \\
\hline Current smoking, $\%$ & 19.5 & 14.7 & 19.8 & $12.6^{\ddagger}$ \\
\hline Regular drinking, \%\# & 13.5 & $10.1^{*}$ & 11.2 & 10.6 \\
\hline Physical activity, $\% \Psi$ & 35.1 & $44.2^{*}$ & 28.9 & 37.9 \\
\hline Tertiary education, \% & 14.3 & 13.1 & 16.8 & 10.7 \\
\hline Anti-hypertensive medication, \% & - & 37.2 & - & 60.2 \\
\hline \multicolumn{5}{|c|}{$\begin{array}{l}\text { Data are expressed as mean } \pm \text { SD or geometric mean }(95 \% \mathrm{Cl}) \text { unless otherwise stated. }{ }^{*} p<0.05,{ }^{\dagger} p<0.01 \text {, and }{ }^{\ddagger} p<0.001 \text { for nor- } \\
\text { motensive versus hypertensive subjects after adjusting for age and sex. "For blood pressures, subjects on anti-hypertensive drug } \\
\text { medications were excluded. "Regular drinking was defined as "at least once a week". "Physical activity was defined as "taking ex- } \\
\text { ercise at least once a week in the past month". }\end{array}$} \\
\hline
\end{tabular}

Table 1: Clinical characteristics of 1,294 subjects as stratified by hypertension status at baseline and followup.

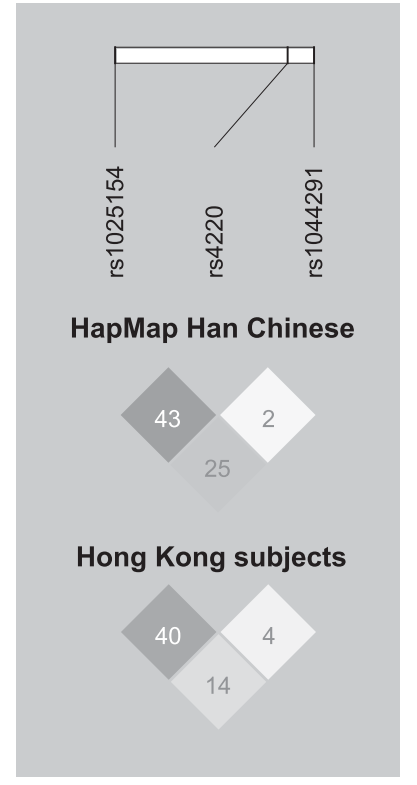

Figure 1: Pairwise LD pattern in Hong Kong subjects and HapMap Han Chinese population. The values shown are the pairwise LD coefficients $\left(r^{2}\right)$ calculated. The darker the colour, the higher is the $r^{2}$ value. (see Supplementary Table 2 available online at www.thrombosisonline.com)

\section{Association with plasma fibrinogen}

In our subjects, minor alleles of both SNPs rs 1025154 and rs4220 were associated with higher plasma fibrinogen level at both baseline and follow-up, even after age and sex adjustment ( Table 2). The association of rs1025154 was not significant after further adjusting for the rs4220 genotype ( $\mathrm{p}=0.705$ and 0.823 at baseline and follow-up, respectively), suggesting its association was due to linkage disequilibrium with rs4220. The association of rs4220 with plasma fibrinogen was significant in both men (regression coefficient $=0.159, \beta=0.171, p<0.001$ at baseline and regression coefficient $=0.097, \beta=0.103, p=0.007$ at follow-up) and women (regression coefficient $=0.109, \beta=0.119, \mathrm{p}=0.001$ at baseline and regression coefficient $=0.151, \beta=0.158, \mathrm{p}<0.001$ at follow-up).

In the haplotype analysis, haplotype TAC (the only haplotype containing the minor allele of rs4220) was significantly associated 
Table 2: Associations of genotypes with fibrinogen level at baseline and follow-up.

\begin{tabular}{|c|c|c|c|c|c|}
\hline \multirow[t]{2}{*}{ SNP } & \multirow[t]{2}{*}{ Genotype } & \multicolumn{2}{|l|}{ Baseline } & \multicolumn{2}{|l|}{ Follow-up } \\
\hline & & $\begin{array}{l}\text { Mean } \pm \text { SD } \\
(g / l)\end{array}$ & $\begin{array}{l}\text { P-value (regression } \\
\text { coefficient, } \beta \text { ) }\end{array}$ & $\begin{array}{l}\text { Mean } \pm \text { SD } \\
(g / l)\end{array}$ & $\begin{array}{l}\text { P-value (regression } \\
\text { coefficient, } \beta \text { ) }\end{array}$ \\
\hline \multirow[t]{3}{*}{ rs1025154 } & $\mathrm{CC}$ & $2.45 \pm 0.57$ & \multirow[t]{3}{*}{$0.001(0.069,0.086)^{*}$} & $2.94 \pm 0.60$ & \multirow[t]{3}{*}{$0.003(0.065,0.079)^{*}$} \\
\hline & СT & $2.54 \pm 0.60$ & & $2.96 \pm 0.57$ & \\
\hline & TT & $2.57 \pm 0.55$ & & $3.05 \pm 0.64$ & \\
\hline \multirow[t]{3}{*}{ rs 4220} & GG & $2.45 \pm 0.56$ & \multirow[t]{3}{*}{$<0.001(0.134,0.144)^{*}$} & $2.92 \pm 0.60$ & \multirow[t]{3}{*}{$<0.001(0.124,0.130)^{*}$} \\
\hline & GA & $2.58 \pm 0.59$ & & $3.00 \pm 0.56$ & \\
\hline & AA & $2.71 \pm 0.61$ & & $3.21 \pm 0.70$ & \\
\hline \multirow[t]{3}{*}{ rs1044291 } & $\mathrm{CC}$ & $2.53 \pm 0.59$ & \multirow[t]{3}{*}{$0.363(-0.031,-0.024)$} & $2.98 \pm 0.59$ & \multirow[t]{3}{*}{$0.628(-0.017,-0.013)$} \\
\hline & CT & $2.47 \pm 0.56$ & & $2.94 \pm 0.62$ & \\
\hline & TT & $2.57 \pm 0.53$ & & $3.00 \pm 0.57$ & \\
\hline
\end{tabular}

All $p$-values were adjusted for age and sex. ${ }^{*} P$-values that can pass multiple testing correction $(p<0.0192)$.

Table 3: Associations of genotypes with hypertension at baseline and follow-up.

\begin{tabular}{|c|c|c|c|c|c|c|c|}
\hline \multirow[t]{3}{*}{ SNP } & \multirow[t]{3}{*}{ Genotype } & \multicolumn{6}{|l|}{ Frequency (\%) } \\
\hline & & \multicolumn{3}{|l|}{ Baseline } & \multicolumn{3}{|l|}{ Follow-up } \\
\hline & & $\begin{array}{l}\text { Normotensive } \\
(n=1,095)\end{array}$ & $\begin{array}{l}\text { Hypertensive } \\
(n=199)\end{array}$ & $\begin{array}{l}\text { P-value } \\
\text { (OR [95\% CI]) }\end{array}$ & $\begin{array}{l}\text { Normotensive } \\
(n=945)\end{array}$ & $\begin{array}{l}\text { Hypertensive } \\
(\mathrm{n}=349)\end{array}$ & $\begin{array}{l}\text { P-value } \\
\text { (OR }[95 \% \mathrm{CI}] \text { ) }\end{array}$ \\
\hline \multirow[t]{3}{*}{ rs1025154 } & CC & 29.2 & 24.6 & \multirow{3}{*}{$\begin{array}{l}0.166(1.18 \\
[0.93-1.50])\end{array}$} & 29.1 & 26.6 & \multirow{3}{*}{$\begin{array}{l}0.114(1.16 \\
[0.96-1.40])\end{array}$} \\
\hline & $\mathrm{CT}$ & 46.9 & 51.8 & & 47.5 & 48.1 & \\
\hline & TT & 23.9 & 23.6 & & 23.4 & 25.2 & \\
\hline \multirow[t]{3}{*}{ rs 4220} & GG & 54.2 & 46.2 & \multirow{3}{*}{$\begin{array}{l}0.004(1.49 \\
[1.13-1.95])^{*}\end{array}$} & 54.6 & 48.7 & \multirow{3}{*}{$\begin{array}{l}0.013(1.32 \\
[1.06-1.63])^{*}\end{array}$} \\
\hline & GA & 39.1 & 44.2 & & 38.7 & 43.0 & \\
\hline & AA & 6.7 & 9.5 & & 6.7 & 8.3 & \\
\hline \multirow[t]{3}{*}{ rs1044291 } & $\mathrm{CC}$ & 77.0 & 84.8 & \multirow{3}{*}{$\begin{array}{l}0.071(0.68 \\
[0.45-1.03])\end{array}$} & 76.9 & 81.6 & \multirow{3}{*}{$\begin{array}{l}0.368(0.87 \\
[0.64-1.18])\end{array}$} \\
\hline & CT & 21.9 & 13.6 & & 22.2 & 16.4 & \\
\hline & TT & 1.1 & 1.5 & & 0.8 & 2.0 & \\
\hline
\end{tabular}

with higher plasma fibrinogen level whereas haplotype CGC (the only haplotype containing the minor allele of rs1025154) was significantly associated with lower level at both baseline and followup (see Supplementary Table 3 available online at www.thrombo sis-online.com). The overall haplotype association with plasma fibrinogen was not significant after controlling for the SNP rs4220 at both baseline $(\mathrm{p}=0.708)$ and follow-up $(\mathrm{p}=0.587)$, suggesting the significant haplotype associations were mainly contributed by the single variant rs4220.

\section{Association with hypertension}

As shown in Table 3, the minor A allele of the SNP rs4220 showed significant association with higher odds of hypertension at both baseline and follow-up $(\mathrm{OR}=1.49, \mathrm{p}=0.004$ and $\mathrm{OR}=1.32$, $\mathrm{p}=0.013$, respectively). In sex-specific analysis, the association of this SNP with hypertension was significant only in men ( $\mathrm{p}=0.024$ at baseline and 0.005 at follow-up), but not in women, although there was a trend towards significance at baseline ( $p=0.059$ at baseline and 0.511 at follow-up). The association of rs4220 with hypertension at baseline remained significant after adjusting for age, sex, BMI, triglycerides (ln-transformed), HDL-cholesterol, HOMA-IR (ln-transformed), two-hour glucose after OGTT (ln-transformed), current smoking, regular drinking, physical activity and tertiary education (OR $[95 \%$ confidence interval $(\mathrm{CI})]=1.52$ [1.09-2.10], $\mathrm{p}=0.014$ ).

The haplotype TAC was significantly associated with higher odds of hypertension at baseline (see Supplementary Table 3 available online at www.thrombosis-online.com). The overall haplotype association with hypertension was not significant after controlling for SNP rs4220 ( $\mathrm{p}=0.362)$, suggesting that the significant haplotype association was mainly contributed by the single variant 


\begin{tabular}{|c|c|c|c|c|c|}
\hline \multirow[t]{2}{*}{ SNP } & \multirow[t]{2}{*}{ Genotype } & \multicolumn{2}{|l|}{ Baseline } & \multicolumn{2}{|l|}{ Follow-up } \\
\hline & & $\begin{array}{l}\text { Mean } \pm \text { SD } \\
(\mathrm{mmHg})\end{array}$ & $\begin{array}{l}\text { P-value (regression } \\
\text { coefficient, } \beta \text { ) }\end{array}$ & $\begin{array}{l}\text { Mean } \pm \text { SD } \\
(\mathrm{mmHg})\end{array}$ & $\begin{array}{l}\text { P-value (regression } \\
\text { coefficient, } \beta \text { ) }\end{array}$ \\
\hline \multicolumn{6}{|c|}{ Systolic blood pressure } \\
\hline \multirow[t]{3}{*}{ rs1025154 } & CC & $116.4 \pm 17.0$ & \multirow[t]{3}{*}{$0.409(-0.474,-0.020)$} & $119.7 \pm 16.5$ & \multirow[t]{3}{*}{$0.702(-0.236,-0.010)$} \\
\hline & CT & $116.0 \pm 17.1$ & & $118.4 \pm 16.9$ & \\
\hline & TT & $114.1 \pm 16.1$ & & $118.0 \pm 15.1$ & \\
\hline \multirow[t]{3}{*}{ rs4220 } & GG & $115.1 \pm 17.1$ & \multirow[t]{3}{*}{$0.110(1.062,0.039)$} & $118.4 \pm 16.9$ & \multirow[t]{3}{*}{$0.208(0.902,0.034)$} \\
\hline & GA & $116.6 \pm 16.1$ & & $119.0 \pm 15.8$ & \\
\hline & $A A$ & $114.5 \pm 18.6$ & & $118.4 \pm 16.5$ & \\
\hline \multirow[t]{3}{*}{ rs1044291 } & CC & $116.5 \pm 17.1$ & \multirow[t]{3}{*}{$<0.001(-3.097,-0.082)^{*}$} & $119.2 \pm 16.2$ & \multirow[t]{3}{*}{$0.026(-2.265,-0.061)$} \\
\hline & CT & $112.3 \pm 15.3$ & & $116.8 \pm 17.1$ & \\
\hline & TT & $114.6 \pm 19.2$ & & $112.8 \pm 9.2$ & \\
\hline \multicolumn{6}{|c|}{ Diastolic blood pressure } \\
\hline \multirow[t]{3}{*}{ rs1025154 } & CC & $73.6 \pm 9.5$ & \multirow[t]{3}{*}{$0.067(-0.659,-0.049)$} & $75.0 \pm 9.9$ & \multirow[t]{3}{*}{$0.774(-0.118,-0.008)$} \\
\hline & CT & $73.1 \pm 10.1$ & & $74.5 \pm 10.6$ & \\
\hline & TT & $71.9 \pm 9.6$ & & $74.5 \pm 10.0$ & \\
\hline \multirow[t]{3}{*}{ rs 4220} & GG & $72.8 \pm 9.8$ & \multirow[t]{3}{*}{$0.814(0.098,0.006)$} & $74.2 \pm 10.1$ & \multirow[t]{3}{*}{$0.019(1.109,0.068)$} \\
\hline & GA & $73.4 \pm 9.7$ & & $75.0 \pm 10.3$ & \\
\hline & $A A$ & $71.4 \pm 10.6$ & & $76.4 \pm 10.9$ & \\
\hline \multirow[t]{3}{*}{ rs1044291 } & $\mathrm{CC}$ & $73.3 \pm 9.9$ & \multirow[t]{3}{*}{$0.006(-1.613,-0.073)^{*}$} & $75.1 \pm 10.1$ & \multirow[t]{3}{*}{$0.002(-2.093,-0.090)^{*}$} \\
\hline & CT & $71.5 \pm 9.4$ & & $73.0 \pm 10.4$ & \\
\hline & TT & $70.5 \pm 10.8$ & & $70.6 \pm 7.7$ & \\
\hline
\end{tabular}

Table 4: Associations of genotypes with blood pressure in subjects not taking antihypertensive medications at baseline $(n=1,220)$ and followup $(n=1,084)$.

Data are expressed as mean \pm SD. All $p$-values were adjusted for age and sex. ${ }^{*}$-values that can pass multiple testing correction $(p<0.0192)$.

rs4220. None of the haplotypes showed significant association with hypertension at follow-up.

\section{Association with blood pressure}

We then tested the association with blood pressure after excluding subjects on anti-hypertensive medications. The minor T allele of the SNP rs1044291 was significantly associated with lower systolic and diastolic blood pressure at baseline $(\mathrm{p}<0.001$ and $\mathrm{p}=0.006$, respectively) (Table 4). A similar association with diastolic blood pressure was found at follow-up. In sex-specific analysis, the association of rs 1044291 with blood pressure was significant in men, but not in women (see Supplementary Table 4 available online at www.thrombosis-online.com). At baseline, the minor A allele of the SNP rs4220 was significantly associated with higher systolic blood pressure in men $(p=0.007)$ and a nominal association was also found at follow-up $(\mathrm{p}=0.029)$. Although the minor $\mathrm{C}$ allele of the SNP rs1025154 was significantly associated with lower diastolic blood pressure in women at baseline $(\mathrm{p}=0.008)$, no significant or nominal association was found at follow-up $(\mathrm{p}=0.276)$.
In haplotype analysis, haplotype TGT was significantly associated with lower systolic and diastolic blood pressure at baseline as well as lower diastolic blood pressure at follow-up (see Supplementary Table 3 available online at www.thrombosis-online.com). Haplotype TAC was significantly associated with higher diastolic blood pressure at follow-up. The overall haplotype associations with blood pressures at both baseline and follow-up (shown in see Supplementary Table 3 available online at www.thrombosis-on line.com) became non-significant after controlling for the SNP rs 1044291 ( $p>0.150$ ), suggesting that the significant haplotype associations were mainly contributed by the single variant rs1044291.

\section{Association with the development of hypertension}

Since SNP rs4220 was associated with both hypertension and plasma fibrinogen level, we investigated whether this genetic variant predicted the development of hypertension at follow-up among subjects who were normotensive at baseline. Among 1,095 normotensive subjects at baseline, 178 subjects had developed hypertension by follow-up. The minor A allele of the SNP rs4220 showed 
significant association with higher odds of developing hypertension after adjusting for baseline age, sex and follow-up duration in men $(\mathrm{OR}[95 \% \mathrm{CI}]=1.52[1.06-2.17], \mathrm{p}=0.022)$, but not in women (OR $[95 \% \mathrm{CI}]=0.97[0.64-1.47], \mathrm{p}=0.877)$. This SNP showed a marginal non-significant sex interaction $(\mathrm{p}=0.082)$. The association in men remained significant after further adjusting for baseline BMI, systolic blood pressure, triglycerides (ln-transformed), HDL-cholesterol, HOMA-IR (ln-transformed), two-hour glucose after OGTT (ln-transformed), current smoking, regular drinking, physical activity and tertiary education (OR $[95 \% \mathrm{CI}]=1.64$ [1.06-2.68], $\mathrm{p}=0.26)$.

\section{Discussion}

In this study, we found that the genetic variants in the FGB gene were associated with plasma fibrinogen, hypertension and blood pressure. We also confirmed the robust association of the genetic variants in the FGB gene with plasma fibrinogen. In all the analyses, we tried to confirm the findings at baseline in the follow-up study. All the main findings presented here were also found at follow-up with significant or nominal associations. Nevertheless, our finding needs confirmation in a larger independent prospective cohort.

It has been suggested that elevated plasma fibrinogen can increase blood viscosity and peripheral vascular resistance, leading to elevated blood pressure (9). The association of plasma fibrinogen with hypertension could also be due to its role in inflammation, hyperinsulinaemia, insulin resistance and arterial stiffness $(7,20)$. As genotypes are randomly assigned at conception, the covariates that typically confound traditional epidemiological studies would less likely act as confounders in genetic association studies and it was suggested that statistical adjustment for genetic associations may be unnecessary (21). Therefore, we only adjusted the findings for age and sex in the primary analysis. Nevertheless, we have adjusted for potential confounding factors in the final models for the association with hypertension.

Two previous prospective studies in Australian and American populations showed significant association of plasma fibrinogen with development of hypertension in men, but not in women (7, 9). Our findings are consistent with these two reports and further demonstrated that this gender difference in the association with development of hypertension could also occur at the genetic level. As rs4220 was associated with plasma fibrinogen level, our data, and those from the other two cohort studies, thus suggest a possible causal relationship of fibrinogen in the development of hypertension, especially in men. The underlying mechanism for this gender difference is unknown. One of the possible explanations may be the large difference in the prevalence of smoking between men and women in Hong Kong compared to Western populations (22). It has been reported that the effect of genetic variants on plasma fibrinogen is more significant in smokers than non-smokers (23). However, in our cohort, adjustment for smoking status did not alter the significant association of rs 4220 with development of hypertension and there is no significant interaction with smoking (data not shown). Moreover, it has been suggested that the gender difference in insulinaemia and insulin resistance, sex hormone, and gender difference in the relationship between blood viscosity and age, may also contribute to this observation (7). Although fibrinogen $\beta$ chain synthesis is the rate-limiting step of the synthesis of mature fibrinogen (4), variants in the genes encoding fibrinogen $\alpha$ and $\gamma$ chains have also been reported to be associated with plasma fibrinogen level $(8,24)$. Moreover, they are also associated with cardiovascular risks $(8,24,25)$.

We observed higher plasma fibrinogen levels in subjects with the minor A allele of the rs 4220 variant. The change of $G$ to A allele in SNP rs4220 leads to substitution of arginine by lysine in exon 8 in the carboxyl terminal of the fibrinogen $\beta$ polypeptide chain and may affect the configuration of this domain (26). This polymorphism was reported to be associated with macrovascular diseases $(23,26,27)$. Moreover, this SNP is in high LD with several SNPs in the gene region, such as rs2227401 (see Supplementary Table 1 available online at www.thrombosis-online.com), which is in perfect LD with the two widely studied SNPs $-455 \mathrm{G}>\mathrm{A}$ ( $\mathrm{rs} 1800790)$ and $-148 \mathrm{C}>\mathrm{T}$ ( $\mathrm{rs} 1800797$ ) (8). In fact, the $-455 \mathrm{G}>\mathrm{A}$ polymorphism can alter the binding of a transactivation protein complex as it is located in an interleukin-6 responsive HNF1 element $(28,29)$. This SNP is also associated with erythrocyte aggregation in men, but not in women $(30)$. The $-148 \mathrm{C}>\mathrm{T}$ polymorphism may also affect the protein expression as it is located near an interleukin- 6 responsive element and is in a putative transforming growth factor- $\beta$ responsive element (31).

Among our subjects not taking anti-hypertensive drugs, SNP rs1044291 was significantly associated with blood pressure. The association of this SNP with hypertension did not reach statistical significance in this study $(\mathrm{p}=0.071$ at baseline and $\mathrm{p}=0.368$ at follow-up). This may be due to insufficient power as the minor $\mathrm{T}$ allele of this SNP is associated with only $2.3-3.1 \mathrm{mmHg}$ decrease in systolic blood pressure and 1.6-2.1 $\mathrm{mmHg}$ decrease in diastolic blood pressure, which are insufficient to cause hypertension after a few years in someone who has blood pressure in the normal range at baseline. However, such decreases in blood pressure are clinically relevant. In middle-aged people, a $2 \mathrm{mmHg}$ reduction in usual blood pressure is associated with $10 \%$ lower mortality from stroke and $7 \%$ lower mortality from ischaemic heart disease or other vascular causes (32). The SNP rs4220 was associated with hypertension, but was not significantly associated with blood pressure, except systolic blood pressure in men at baseline. In the analysis of the association with blood pressure, excluding subjects taking antihypertensive drugs could reduce power because of the loss of subjects with a more extreme phenotype. The involvement of multiple genes and gene-environment interaction in the aetiology of hypertension may also make the scenario more complex. Nevertheless, our study demonstrates the positive association of rs4220 with development of hypertension at follow-up in men. The significant association of the SNP rs1025154 with diastolic blood pressure in women at baseline could have arisen by chance due to its non-significant $\mathrm{p}$-value at follow-up. This highlights the importance of using the follow-up data for confirmation. 


\section{What is known about this topic?}

- Genetic variants in the gene encoding the fibrinogen $\beta$ chain are associated with plasma fibrinogen level.

- There were two prospective studies which reported positive association of plasma fibrinogen with incident hypertension in men, but not in women.

\section{What does this paper add?}

- Genetic variants in the gene encoding the fibrinogen $\beta$ chain are associated with prevalent and incident hypertension, especially in men.

- This study suggests a possible causal role of fibrinogen in hypertension development.

Among the four ethnic populations (Han Chinese, Japanese, European and African) in the HapHap project, all three SNPs genotyped in this study have ethnic differences in the MAF. For example, the MAF of rs 4220 ranges from 0.083 in African, 0.125 in Japanese, 0.178 in Han Chinese to 0.208 in European populations. Even within China, the MAF of this SNP among subjects without coronary artery disease differs by region, ranging from 0.071 in Shanxi to 0.276 in Guangdong, which is comparable to the MAF of 0.270 found in this study (33). This MAF is slightly higher than the MAF of $0.21-0.23$ in European populations for rs222740 and rs1800790, which are in complete LD with rs4220 $(8,34)$. It has also been reported that plasma fibrinogen level is higher among South Asians than Caucasians in the United Kingdom, independent of genetic variants in the FGB gene (35). Ethnic differences in plasma fibrinogen level and MAF of genetic variants may explain the differences between this study and a recent German study that showed no association of genetic variants with hypertension (8). Nevertheless, our results are consistent with other studies showing that SNP rs4220 or its closely related SNPs such as rs 1800790 are significantly associated with plasma fibrinogen level $(6,8,23,35$, 36). In a previous meta-analysis, it was noted that a study in China showed greater effect size of rs1800790 on coronary heart disease risk than other studies (6). Although meta-analyses involving mainly American and European populations did not reveal strong associations of $F G B$ SNPs with cardiovascular diseases $(6,37)$, meta-analyses of studies in Chinese revealed significant associations $(33,38,39)$. In addition, this SNP is associated with coronary heart disease in type II diabetic patients in our population (40).

There are some limitations in this study. The number of hypertensive cases in the study cohort was low relative to the controls, and so affected the power of this study. In addition, the exact time of the development of hypertension was unknown. Although the MAF of the SNP rs1025124 in this study is higher than that in the HapMap Han Chinese population, there is no significant difference in the pairwise LD pattern. Therefore, the tagging SNPs genotyped are representative of both populations.

In conclusion, the SNP rs4220 in the FGB gene is associated with plasma fibrinogen level and prevalent hypertension in Hong
Kong Chinese. This SNP is also associated with development of hypertension after 6.4 years in men, though not in women. This suggests a possible causal role of fibrinogen in hypertension development, especially in men. Further studies such as replication in another Chinese population would be desirable.

\section{Acknowledgements}

We thank the Genome Research Centre, The University of Hong Kong for their support of genotyping and all the study participants.

\section{References}

1. Ernst E, Resch KL. Fibrinogen as a cardiovascular risk factor: a meta-analysis and review of the literature. Ann Intern Med 1993; 118: 956-963.

2. Imperatore $\mathrm{G}$, Riccardi $\mathrm{G}$, Iovine $\mathrm{C}$, et al. Plasma fibrinogen: a new factor of the metabolic syndrome. A population-based study. Diabetes Care 1998; 21: 649-654.

3. Fibrinogen Studies Collaboration, Danesh J, Lewington S, Thompson SG, et al. Plasma fibrinogen level and the risk of major cardiovascular diseases and nonvascular mortality: an individual participant meta-analysis. J Am Med Assoc 2005; 294: 1799-1809.

4. Roy SN, Mukhopadhyay G, Redman CM. Regulation of fibrinogen assembly. Transfection of Hep G2 cells with B beta cDNA specifically enhances synthesis of the three component chains of fibrinogen. J Biol Chem 1990; 265: 6389-6393.

5. Kant JA, Fornace AJ, Jr, Saxe D, et al. Evolution and organization of the fibrinogen locus on chromosome 4: gene duplication accompanied by transposition and inversion. Proc Natl Acad Sci USA 1985; 82: 2344-2348.

6. Smith GD, Harbord R, Milton J, et al. Does elevated plasma fibrinogen increase the risk of coronary heart disease? Evidence from a meta-analysis of genetic association studies. Arterioscler Thromb Vasc Biol 2005; 25: 2228-2233.

7. Shankar A, Wang JJ, Rochtchina E, et al. Positive association between plasma fibrinogen level and incident hypertension among men: population-based cohort study. Hypertension 2006; 48: 1043-1049.

8. Kolz M, Baumert J, Gohlke H, et al. Association study between variants in the fibrinogen gene cluster, fibrinogen levels and hypertension: results from the MONICA/KORA study. Thromb Haemost 2009; 101: 317-324.

9. Folsom AR, Peacock JM, Nieto FJ, et al. Plasma fibrinogen and incident hypertension in the Atherosclerosis Risk in Communities (ARIC) Study. J Hypertens 1998; 16: $1579-1583$

10. Cheng J, Zhao D, Wang W, et al. Association between plasma fibrinogen concentration and ten-year change in blood pressure. Zhonghua Yi Xue Za Zhi 2008; 88: 2263-2266 (in Chinese).

11. Wong LY, Ong KL, Cheung BM, et al. Polymorphisms of the fibrinogen-beta gene are related to 2-hour glucose level after oral glucose tolerance test in Hong Kong Chinese. Dis Markers 2008; 24: 167-173.

12. Cheung BM, Wat NM, Tso AW, et al. Association between raised blood pressure and dysglycemia in Hong Kong Chinese. Diabetes Care 2008; 31: 1889-1891.

13. Cheung BM, Wat NM, Man YB, et al. Development of diabetes in Chinese with the metabolic syndrome: a 6-year prospective study. Diabetes Care 2007; 30: 1430-1436.

14. Cheung BM, Wat NM, Tam S, et al. Components of the metabolic syndrome predictive of its development: a 6-year longitudinal study in Hong Kong Chinese. Clin Endocrinol (Oxf) 2008; 68: 730-737.

15. Ong KL, Leung R, Wong LY, et al. Association of F11 receptor gene polymorphisms with central obesity and blood pressure. J Intern Med 2008; 263:322-332.

16. The International HapMap Consortium. The International HapMap Project. Nature 2003; 426: 789-796.

17. Barrett JC, Fry B, Maller J, et al. Haploview: analysis and visualization of LD and haplotype maps. Bioinformatics 2005; 21: 263-265.

18. Purcell S, Neale B, Todd-Brown K, et al. PLINK: a tool set for whole-genome association and population-based linkage analyses. Am J Hum Genet 2007; 81: 559-575.

19. Nyholt DR. A simple correction for multiple testing for single-nucleotide polymorphisms in linkage disequilibrium with each other. Am J Hum Genet 2004; 74 : 765-769. 
20. Engström G, Janzon L, Berglund G, et al. Blood pressure increase and incidence of hypertension in relation to inflammation-sensitive plasma proteins. Arterioscler Thromb Vasc Biol 2002; 22: 2054-2058.

21. Smith GD, Lawlor DA, Harbord R, et al. Clustered environments and randomized genes: a fundamental distinction between conventional and genetic epidemiology. PLoS Med 2007; 4: e352.

22. Cheung BM, Li M, Ong KL, et al. High density lipoprotein-cholesterol levels increase with age in American women but not in Hong Kong Chinese women. Clin Endocrinol (Oxf) 2009; 70: 561-568.

23. Behague I, Poirier O, Nicaud V, et al. Beta fibrinogen gene polymorphisms are associated with plasma fibrinogen and coronary artery disease in patients with myocardial infarction. The ECTIM Study. Etude Cas-Temoins sur l'Infarctus du Myocarde. Circulation 1996; 93: 440-449.

24. Sie MP, Isaacs A, de Maat MP, et al. Genetic variation in the fibrinogen-alpha and fibrinogen-gamma genes in relation to arterial stiffness: the Rotterdam Study. J Hypertens 2009; 27: 1392-1398.

25. Cheung EY, Bos MJ, Leebeek FW, et al. Variation in fibrinogen FGG and FGA genes and risk of stroke: the Rotterdam Study. Thromb Haemost 2008; 100: 308-313.

26. Scott EM, Ariëns RA, Grant PJ. Genetic and environmental determinants of fibrin structure and function: relevance to clinical disease. Arterioscler Thromb Vasc Biol 2004; 24: 1558-1566.

27. Carter AM, Catto AJ, Bamford JM, et al. Gender-specific associations of the fibrinogen B beta 448 polymorphism, fibrinogen levels, and acute cerebrovascular disease. Arterioscler Thromb Vasc Biol 1997; 17: 589-594.

28. Brown ET, Fuller GM. Detection of a complex that associates with the Bbeta fibrinogen G-455-A polymorphism. Blood 1998; 92: 3286-3293.

29. Humphries SE, Cook M, Dubowitz M, et al. Role of genetic variation at the fibrinogen locus in determination of plasma fibrinogen concentrations. Lancet 1987; 329: 1452-1455.

30. Ben Assayag E, Bova I, Berliner S, et al. Gender differences in the expression of erythrocyte aggregation in relation to B beta-fibrinogen gene polymorphisms in apparently healthy individuals. Thromb Haemost 2006; 95: 428-433.
31. Thomas A, Lamlum H, Humphries S, et al. Linkage disequilibrium across the fibrinogen locus as shown by five genetic polymorphisms, G/A-455 (HaeIII), C/T-148 (HindIII/AluI), T/G+1689 (AvaII), and BclI (beta-fibrinogen) and TaqI (alpha-fibrinogen), and their detection by PCR. Hum Mutat 1994; 3: 79-81.

32. Lewington S, Clarke R, Qizilbash N, et al. Age-specific relevance of usual blood pressure to vascular mortality: a meta-analysis of individual data for one million adults in 61 prospective studies. Lancet 2002; 360:1903-1913.

33. Chen $\mathrm{X}, \mathrm{Xu} \mathrm{M}$, Jin $\mathrm{L}$, et al. Association of beta-fibrinogen gene $-148 \mathrm{C} / \mathrm{T}$ and $-455 \mathrm{G} / \mathrm{A}$ polymorphisms and coronary artery disease in Chinese population: a meta analysis. Sci China C Life Sci 2008; 51:814-20.

34. Hoppe B, Tolou F, Dörner T, et al. Gene polymorphisms implicated in influencing susceptibility to venous and arterial thromboembolism: frequency distribution in a healthy German population. Thromb Haemost 2006; 96: 465-470.

35. Kain K, Blaxill JM, Catto AJ, et al. Increased fibrinogen levels among South Asians versus Whites in the United Kingdom are not explained by common polymorphisms. Am J Epidemiol 2002; 156: 174-179.

36. Carty CL, Cushman M, Jones D, et al. Associations between common fibrinogen gene polymorphisms and cardiovascular disease in older adults. The Cardiovascular Health Study. Thromb Haemost 2008; 99: 388-395.

37. Keavney B, Danesh J, Parish S, et al. Fibrinogen and coronary heart disease: test of causality by 'Mendelian randomization'. Int J Epidemiol 2006; 35: 935-943.

38. Chen XC, Xu MT, Zhou W, et al. A meta-analysis of beta-fibrinogen gene-455G/A polymorphism and plasma fibrinogen level in Chinese cerebral infarction patients. Biomed Environ Sci 2007; 20: 366-372.

39. Xu X, Li J, Sheng W, et al. Meta-analysis of genetic studies from journals published in China of ischemic stroke in the Han Chinese population. Cerebrovasc Dis 2008; 26: 48-62.

40. Lam KS, Ma OC, Wat NM, et al. Beta-fibrinogen gene G/A-455 polymorphism in relation to fibrinogen concentrations and ischaemic heart disease in Chinese patients with type II diabetes. Diabetologia 1999; 42: 1250-1253. 